\title{
Study on Uygur Folk Dastan from the Perspective of Belt and Road"*
}

\author{
Rousitaimujiang Abudouriyimu \\ Uygur College of Language and Culture \\ Northwest Minzu University \\ Lanzhou, China 730030
}

\author{
Aili Tuxunayi \\ Inistitute of Social Sciences \\ Northwest Minzu University \\ Lanzhou, China 730030
}

\begin{abstract}
As a cultural heritage of China, Uygur folk Dasitan is a precious treasure left by the ancient Silk Road and a witness of civilization exchanges and mutual learning. This paper compares the genre, structure and image of Uygur folk Dastan and the folk narrative poems along the Silk Road Economic Belt, revealing the role of Uygur folk Dastan in the "Silk Road Economic Belt", especially the "people-to-people exchanges".
\end{abstract}

Keywords-Uygur folk Dastan; silk road economic belt; people-to-people exchanges; cultural mutual learning

\section{INTRODUCTION}

As an organic combination of text, music and singing art, folk Dastan is one of the priceless treasures in the treasure house of Chinese culture, narrating large-scale events orally. It is a special form of literature and art shared by the Uygur, Kazakh, Mongolian and Tibetan minorities across ethnic groups and countries. It is the quintessence of the wisdom of the toilers, inheriting the social history, moral concepts, aesthetics, folklore, culture, art and language of its own nation in the formalized style. Therefore, inheriting and propagating such a good culture has important practical significance for protecting the diversity of regional culture, strengthening cultural exchanges among ethnic groups, strengthening mutual understanding and national unity, safeguarding social stability in frontiers, prospering economy development and revitalizing culture.

Xinjiang was originally the front line of the strategy of developing the western region. Now, driven by the strategy of the Silk Road Economic Belt", it has changed from the geographical center of the Asian continent to the hub of AsiaEurope transportation and the heartland of economic and cultural cooperation between Asia and Europe. "Xinjiang has become a pearl on the ancient Silk Road with its splendid historical and cultural heritage. The cultures of all ethnic groups in Xinjiang are based on Chinese culture, combining Eastern and Western cultures, while preserving oasis and

*1.This paper is a phased achievement of the $\mathrm{Ph}$. D. program of Northwest Minority Literature Research Center in 2018 - "Research on the Morphology of Uygur Folk Dastan Stories" (Project Code: 2018004B);

2. This paper is a phased research results of the 2015 National Social Science Fund Western Project - "Special Study of Uygur Folk Oral Poetics" (Grant No. 15BZW196).

3. This paper is a phased achievement of postgraduate innovation project of Northwest Minzu University Uyghur Folk Love Dastan Study from the Perspective of the Belt and Road" [Yxm2017004]. grassland cultures. They are regional cultures with multipolarity and multi-development formed by coexistence of various religious cultures." 1 This culture of multiplicity, pluralism and multi-polarity has a positive impact on the "people-to-people exchanges".

The following will be a discussion of the influence of Uygur folk Dastan on the "people-to-people exchanges" with the clue of the traditional oral cultural heritage of Dastan.

\section{GENRE RESEARCH}

The term "Dastan" in Uighur refers to the literary works that describe an event in the form of poetry. It includes Yusuf Has Agifu's Fule Wisdom, Alihir Nawayi's Palhard and Xiren, Abdul Reimu Nizali's Rebiye and Saiding, and other works in written literature, as well as oral literary works of Alip and Senem, and, Yusupu Aihemeiti, Yuelika and Hemrajan etc. sung by civilian Dastan Qi. But there is some difference between written Dastan and oral Dastan. Folk Dastan is a complex art form that includes text with a complete structure, which is sung by Dastan Qi with music. In addition, external factors such as the location, where Dastan is performed and the audience have a certain influence on the singing activities.

Uzbek also have Dastan and it uses such terms as "epos" or "dastan" for this genre. With the characteristics of length, variety of events, and originality of narrative, Uzbek Dastan is divided into heroic epics, romantic epics and historical epics; romantic epics consist of five types: letter of challenge, heroic romantic epic, love romantic epic, life romantic epic and written epic; historical epics is composed of four categories: historical heroic epics, historical fantasy epics, historical specific epics or new epics and biographical epics ${ }^{2}$. Although this taxonomy is not very similar to that of Uygur Dastan, the content, structure and narrative methods don't show great difference compared to those of Uygur Dastan due to linguistic, cultural and geographical factors.

Kazakh folk Dastan plays an important role in its folk literature. So far, 250 Kazakh folk Dastan have been collected. The Kazakh language uses such terms as "jir", "epos", "dastan"

Abdourzezak Sayimu: "Western Culture in the Silk Road Economic Belt", Social Science Research on Xinjiang, 2014 (2).

Imanov etc. Folk Oral Creation in Uzbek, Uzbekistan Teachers Publishing House, 1990; 87. 
and "qisse" for this genre. "Jir" is one of the oldest forms in Kazakh literature, which can be divided into heroic jir and love jir in terms of contents. In addition, Kazakh literature also contains poems with historical themes and poems adapted from Dastan of other nationalities around it, which are now called "Dastan" uniformly. Kazakh folk Dastan is divided into two parts in form: formalized style and narrative style. The metrical style is sung by tamboura music. As Kazakhs are located in the central region of Central Asia, they are linguistically close to the Turks around them. The folk literature of other ethnic groups includes various versions of Kazakh folk Dastan.

As one of the ancient ethnic minorities in China, the Kirgiz have created rich cultural heritage in the long-term historical development. Through these cultural heritages, they record the history of battles, migrations, and natural disasters and so on, and pass these cultural heritage and ideas on to future generations. ${ }^{3}$ Most of the folk Dastan of Kirgiz nationality are heroic epics, among which Epic of Manas belongs to the first batch that were included in the list of national intangible cultural heritage, and UNESCO was placed in the list of human intangible cultural heritage in 2009. Besides that, Kirgiz folk literature has a kind of work, which is smaller than Manas in length. It is a kind of style that combines formalized style with narrative style, called "jomuq". Kirgiz folk literature includes various genres of Manas, which are not different from the Uygur, Uzbek and Kazakh nationalities.

"Dastan" is also a very important genre in Tukman literature. In Tukman literature, metrical style and narrative style are integrated and coexist in written and oral literature as "dastan". In Tukman language, written narrative poems are called "dastan" and folk narrative poems are called "halk dastan". Tukman Dastan enjoys an important position in Tukman folk literature, divided into "heroic epics" and "love epics".

In short, -dastan" is a term common to all ethnic literature in Central Asia. This commonality in genre requires us to pay attention to the cultural exchanges among the various ethnic groups in Central Asia and it provides a good factor for the Silk Road Economic Belt" strategy. If we attach importance to cultural exchanges from ancient times to the present in the field of research, first of all, this will open up new research space for Uyghur folk literature study; secondly, this academic exchange offers a favorable context for the "people-to-people exchanges" project.

\section{STRUCTURAL RESEARCH}

Up to now, 100 Uygur folk Dastan have been collected, of which 65 have been published publicly. ${ }^{4}$ These Dastan's structures have certain rules and characteristics, which are not only belonging to the Uighur folk Dastan.

After comparing the epic poems of the northern Chinese nation, the famous Dastan researcher Lang Ying combines the

Adiri Jumatur. A Study of the Epic Poet Singer of Manas[M]. Nationalities Publishing House, 2006: 241.

4 Abdulwaili Keremu. A Study on Uygur Folk Oral Dastan[M]. China Social Science Publishing House, 2016:7 structure of the epic into: the miraculous birth of the hero-the hard childhood-the contribution of childhood - get into married- the heroic attack or the battle - encounter the difficulty - the hero's hometown is suffering - the enemy's failure - the hero returns to his hometown; ${ }^{5}$ the above nine matrix organizations are the structure of the folk narrative poems of the northern ethnic groups belonging to the Altaic language family in China or the main matrix of these folk narrative poems. It is noteworthy that Orlov, a former Soviet researcher, combined the matrix of Turkic national narrative poems as follows: 1 . The childless King owns children by praying; 2 . The hero fights for a beautiful princess; 3 . The hero tracks the enemy who robs his lover; 4 . The hero escapes from danger or prison with the help of another girl; 5 . The hero's horse smells the hero and runs out of the stables; 6 . The hero rescues the cowardly brother; 7. The hero's foster brother schemes against the hero; 8 . The adopted son takes advantage of the hero's absence to get the regime or marry the hero's lover as his wife; 9 . The hero turns into a beggar and returns to his hometown and so forth.

It can be seen from this that Chinese researcher Lang Ying and the former Soviet Union's matrix taxonomy have certain similarities, that is, both classifications include matrix of birth, childhood, expedition, difficulty and regression etc., which are the main matrixes of the Uygur folk Dastan.

The main matrixes of Uygur folk Dastan's King Kemal and Princess Shems are as follows: 1. The childless king has children through praying; 2 . The birth and name of heroes; 3 . The hero's peculiar love for inamorato; 4 . The hero goes for battles; 5 . The hero gets the help of another girl; 6. Difficulties; 7. The lovers are united; 8 . The hero returns to his hometown; In addition, the structure of love epics such as Sanubar, Yuelika and Hemrajan is similar.

The following are the main matrixes of the heroic epic Goure Augury: 1. Magical pregnancy; 2. Birth in the grave; 3. Born at the same time with the horse; 4. Difficulties in growing up; 5. Getting a sword; 6. Difficulties in going out to battle; 7. Predictive dreams; 8 . Getting a lover; 9. Returning home and gaining power. In addition, heroic epics such as "Qintiemur" and "Alpamij" have the same matrix. It can be seen that the main matrixes of heroic epic and love epic are the same in essentials while differing in minor points, namely the names of people, places, the sequence of events and other details that do not affect the structure of the plot.

There are also some Dastans in the Uygur folk Dastan, which are the same as other Turkic national literature, Persian and Arabic literary epics. These Dastans are collectively titled as "the epic of international themes." Such as: Alip and Senem, Palhard and Xiren, Lylie and McGinnon, Yusupu and Zileha, Yusupu Aihemeiti and so on. All ethnic groups have combined their own epic content with their geographical environment, social situation, history and culture, and customs to form their own versions. These epics have the following characteristics: 1) this kind of epic coexists in written and oral literature; 2) the same epic has the same organizational structure in different

1999: 21-23 
national literary versions; 3 ) the images in the epic are the same in both written and oral literature.

It can be seen that Uygur folk Dastan is an international topic. Because some Dastan spreads pretty widely, a comparative study of the versions between different ethnic groups will provide a good research space for folk literature as well as an important communication platform for the "Silk Road Economic Belt" strategy, playing an important role in the project of people-to-people exchanges".

\section{IMAGE RESEARCH}

The image has two meanings: first, it refers to the characters in the literary works; that is, the typical roles in the works. Such as: Jia Baoyu and Lin Daiyu in "Dream of Red Mansions", Song Jiang, Lin Chong and Wu Song in "Water Margin" and some other typical characters. Second, it means the comprehensive influence or imagination, the recognition of the common culture and the common understanding of a certain thing by a certain nation. For example, the words of "Spanish image", "brilliant image" of hero and "beautiful image" left by something to us are often used by people. ${ }^{6}$ These are images in a broad sense.

Both the heroic image and the bottom-level figures in Dastan gather the understanding of nature and society, desire, pure love and humanity and heroism of the nations themselves. Due to the same geographical environment and cultural factors, the literatures of Uyghur and various ethnic groups in Central and West Asia have deep exchanges, which have caused the mutual migration of literary works and images. Studying image migration and common image is conducive to deepening the exchange of Chinese and Arab and Persian literature as well as healthy development of Chinese and Central Asian literature research. Moreover, it provides a good opportunity for the construction of academic exchanges in the Belt and Road". Taking the Uygur folk Dastan's "Lylie and McGinnon" as an example, the masterpiece is the most Oriental love tragedy so that western minds think that it is "the oriental Romeo and Juliet". The story of Lylie and McGinnon is adapted from a love story that happened in the Arabian Peninsula in the 8th century. It expresses the love concept of the Arab poet Keith in the late 7th and early 8th centuries, and finally becomes an Arab folk story.

The influence of this Dastan can be seen from the use of the word "McGinnon" and its derivatives and idioms. The definition of "McGinnon" in the Modern Uighur Detailed Dictionary is (1) name, be wandering because of love, hermit; (2) shape, loss of reason, no consciousness, madman; (3) man's name. "McGinnon" means "losing reason and turning into a madman because of love." ${ }^{7}$ In the dictionary, one also has access to see the definitions of the words "mejnunlarqe" and "mejnunluk". There is a willow called "mejnuntal" in Xinjiang. The branches of this willow are very thin, and it drifts very hard when there is even a little wind, which reminds us of

\footnotetext{
Wang Xinjian, Liu Shujuan. A Coursebook of Comparative Literature[M], University of Electronic Science and technology of China Edited by Xinjiang National Language Committee: Modern Uighur Detailed Dictionary, Nationalities Publishing House: 1995:85-86
}

McGinnon wandering outside because of love, thin only as bones.

In addition, the word "Lylie" is commonly used with "beautiful lover" and "beautiful woman". Folk people also have the idiom "looking at Lylie needs McGinnon's eyes" (the meaning of this idiom is similar to the Chinese idiom "Beauty is in the eye of a lover"). The word "Lylie" can also be seen in many lyrics. From this it can be seen that the images of "McGinnon" and "Lylie" in Arab legends have become wellknown images on the basis of first entering into written literature, then from written literature into oral literature, "Lylie and McGinnon", which belongs to folk Dastan.

In a word, what Uygur folk Dastan shares with Central Asia, Arabia and Persia is the precious legacy left by the ancient Silk Road, and the self-improvement of Uygur folk literature and Uygur culture in thousands of years of historical development. The positive impact of above-mentioned characteristics of Uyghur folk Dastan on the current "One Belt and One Road" policy, especially the "people-to-people exchanges" project can be summarized as follows:

- The study of Uygur folk Dastan under the vision of One Belt, One Road" is conducive to mutual understanding and mutual trust. The people-to-people exchanges" project requires the following three realms: "the first is to enhance mutual understanding. We must have an in-depth understanding of all aspects of other countries and let the international community fully understand China. The second is to form a good feeling on the basis of understanding, build friendship and deepen mutual trust. Finally, it is necessary to strive to form a consensus on the global governance model, especially the cooperation and win-win concept advocated by China, and build a community of human destiny." ${ }^{8}$ This shows that the key to "people-to-people exchanges" is mutual understanding. These commonalities of Uygur Dastan, as China's oral cultural heritage, naturally arouse the interest of the people of all ethnic groups along the Silk Road Economic Belt and guide them to a deeper understanding of China. These commonalities in Dastan serve as a bridge for us to better know about the cultures and literature of all ethnic groups along the border of the Silk Road Economic Belt. This twoway effect opens the way for mutual trust in the future. Understanding and trust will naturally lead to cooperation.

- From the perspective of the Silk Road Economic Belt, the study of Uygur folk Dastan is conducive to strengthening friendship and academic cooperation handed down from ancient times. The main line and core task of the "One Belt and One Way" project is economic relations, but the economic relationship is not the whole content of the project. Only by properly handling the relationship between economic relations

Li Ziguo. The Integration Point of People-to-People Exchanges under the Vision of $€$ ne Belt, One Road" [J].Journal of Xinjiang Normal University, 2016(5). 
and humanistic exchanges can we ensure the "peopleto-people exchanges". Therefore, in the implementation of the "Belt and Road" strategy, it's wise to pay attention to humanities exchanges, academic cooperation, academic exchanges, public opinion and propaganda work with other countries. The commonalities between the Chinese Uygur folk Dastan and the folk Dastan of the countries along "Belt and Road" provide an unprecedented opportunity for academic exchanges and cooperation. The seminar on the theme of $\Theta$ ne Belt and One Road", the communication between Dastan Qi (the person who sing Dastan) and the researcher of Dastan, the cooperation of researches on Dastan and other activities also drive the progress of "people-to-people exchanges" project positively.

- Under the vision of the "Silk Road Economic Belt", Uygur folk Dastan will serve as a bridge in introducing China and telling the story of China. Some scholars believe that the Belt and Road" is more a cultural phenomenon than an economic phenomenon. In the monographic study of the project of people-topeople exchanges", telling Chinese stories well is advocated strongly. In order to get better results, it's necessary to start with stories that others can understand. The love story of Palhard and Xiren happened between Palhard, the son of the Qin King, and Xiren, the princess of a certain country, is a wellknown story of all nationalities along the Silk Road Economic Belt. As an intangible cultural heritage of China, Uygur folk Dastan has an incomparable significance in building up the "One Belt and One Road" system in cultural exchanges, academic exchanges and academic cooperation. Only by doing this research can we tell a good story about China and create good conditions for the construction of regional cultural exchange platform.

- The study of Uyghur folk Dastan from the perspective of "One Belt and One Road" helps for mutual complementarity and common development. Although the Uygur folk Dastan has been enriching its content under the influence of the ancient Silk Road, more and more brilliant, but our research on it has been in a unidirectional state. If comparing Uygur folk Dastan with other ethnic Dastan in the view of "Silk Road Economic Belt", it can be find out the similarities and differences, which will be helpful for us to study Uygur folk Dastan more deeply and make up for the shortcomings in this respect. In such way, the depth and authority of research can be increased. That is to say, not only Uygur folk Dastan provides favorable conditions for the construction of "One Belt and One Road", but also the construction of "One Belt and One Road" has a positive impact on Uyghur folk studies. According to General Secretary $\mathrm{Xi}$ Jinping's instructions, "Civilization is colorful because of communication, and rich because of mutual learning. The exchange of civilizations and mutual learning is an important driving force for the progress of human civilization and the peaceful development of the world." ${ }^{9}$ Of course, the role of Uygur folk Dastan in the project of "people-to-people exchanges" not only belongs to Dastan, but also belongs to other genres of folk literature, including Uygur material and intangible cultural heritage of Uygur 12 Muqam, Uygur handicraft, Uygur architectural culture and so on, which have a positive impact on "people-to-people exchanges" project. Because the theme of this paper and the author's research direction is folk Dastan, this paper mainly analyses the influence and role of folk Dastan. If other aspects of research are also realized one after another, it will provide a solid theoretical basis for the project of people-to-people exchanges ".

\section{CONCLUSION}

In short, "people-to-people exchanges" is the social foundation for the construction of "One Belt and One Road". For Chinese people, "One Belt and One Road" is far more than an economic event. More importantly, it is a cultural event, and a symbol of the rise of Chinese civilization. The construction of the Belt and Road" will not only bring economic prosperity to the people along the line, but also bring about cultural prosperity. To create a harmonious atmosphere of intercultural dialogue, let the folk Dastan as a cultural heritage become a discourse resource for communication, cooperation and mutual understanding, it is necessary to talk about the "Chinese story" and the "human story". Only in this way can the environment, capacity and modalities of intercultural dialogue and peace culture building be improved at the local, national, bilateral or multilateral, regional or subregional levels. The cultural exchanges and mutual understanding between China and Central Asian countries are moving towards a new stage, and the inheritance, protection and research of the folk Dastan will also open up more room for development in the context of cultural sharing and international exchange.

\section{REFERENCES}

[1] Abdourzezak Sayimu: "Western Culture in the Silk Road Economic Belt", Social Science Research on Xinjiang, 2014 (2).(in Chinese)

[2] Imanov etc. Folk Oral Creation in Uzbek, Uzbekistan Teachers Publishing House, 1990; 87. (in Chinese)

[3] Adiri Jumatur. A Study of the Epic Poet Singer of Manas [M] Nationalities Publishing House, 2006: 241. (in Chinese)

[4] Abdulwaili Keremu. A Study on Uygur Folk Oral Dastan [M]. China Social Science Publishing House, 2016:7.(in Chinese)

[5] Lang Ying. On "Manas" [M].Inner Mongolia University Press, 1999: 21-23. (in Chinese)

[6] Wang Xinjian, Liu Shujuan. A Coursebook of Comparative Literature [M], University of Electronic Science and technology of China. (in Chinese)

[7] Xinjiang National Language Committee: Modern Uighur Detailed Dictionary, Nationalities Publishing House: 1995:85-86. (in Chinese)

\footnotetext{
9 Xi Jinping. Speech at UNESCO headquarters [EB/OL].

ttp://news.xinhuanet.com/politics/2014-03/28/c $119982831 \quad 2 . h t m, 2017-$ 06-15.
} 
[8] Li Ziguo. The Integration Point of People-to-People Exchanges under the Vision of - ne Belt, One Road" [J].Journal of Xinjiang Normal University, 2016(5). (in Chinese)

[9] Xi Jinping. Speech at UNESCO headquarters [ EB/OL ] . ttp://news.xinhuanet.com/politics/2014 - 03/28/c $119982831 \quad 2 . \mathrm{htm}$, 2017-06-15. (in Chinese) 